\title{
TGF $\beta$ signaling plays a critical role in promoting alternative macrophage activation
}

\author{
Dapeng Gong ${ }^{1}$, Wei Shi ${ }^{2}$, Sun-ju Yi ${ }^{1}$, Hui Chen ${ }^{2}$, John Groffen ${ }^{1}$ and Nora Heisterkamp ${ }^{1 *}$
}

\begin{abstract}
Background: Upon stimulation with different cytokines, macrophages can undergo classical or alternative activation to become M1 or M2 macrophages. Alternatively activated (or M2) macrophages are defined by their expression of specific gene products and play an important role in containing inflammation, removing apoptotic cells and repairing tissue damage. Whereas it is well-established that IL-4 can drive alternative activation, if lack of TGF $\beta$ signaling at physiological levels affects M2 polarization has not been addressed.

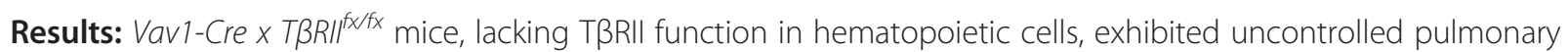
inflammation and developed a lethal autoimmune syndrome at young age. This was accompanied by significantly increased numbers of splenic neutrophils and T cells as well as elevated hepatic macrophage infiltration and bone marrow monocyte counts. TRRII ${ }^{--} \mathrm{CD} 4^{+}$and $\mathrm{CD} 8^{+}$T-cells in the lymph nodes and spleen expressed increased cell surface CD44, and CD69 was also higher on CD4 ${ }^{+}$lymph node T-cells. Loss of TRRIl in bone marrow-derived macrophages (BMDMs) did not affect the ability of these cells to perform efferocytosis. However, these cells were defective in basal and IL-4-induced $\arg 1 \mathrm{mRNA}$ and Arginase-1 protein production. Moreover, the transcription of genes that are typically upregulated in M2-polarized macrophages, such as ym1, mcr2 and mgl2, was also decreased in peritoneal macrophages and IL-4-stimulated TRRI/ $/^{-}$BMDMs. We found that cell surface and mRNA expression of Galectin-3, which also regulates M2 macrophage polarization, was lower in TBRII/- BMDMs. Very interestingly, the impaired ability of these null mutant BMDMs to differentiate into IL-4 polarized macrophages was Stat6- and Smad3-independent, but correlated with reduced levels of phospho-Akt and $\beta$-catenin.

Conclusions: Our results establish a novel biological role for TGF $\beta$ signaling in controlling expression of genes characteristic for alternatively activated macrophages. We speculate that lack of TBRII signaling reduces the anti-inflammatory M2 phenotype of macrophages because of reduced expression of these products. This would cause defects in the ability of the M2 macrophages to negatively regulate other immune cells such as T-cells in the lung, possibly explaining the systemic inflammation observed in Vav1-Cre $x$ TRRIIf ${ }^{f(f x}$ mice.
\end{abstract}

Keywords: TGF $\beta$, Macrophage polarization, Lung, Alveolar macrophage, M1, M2, Hematopoietic, Inflammation, TGFBR2, LGALS3

\section{Background}

Transforming growth factor beta (TGF $\beta$ ) is a multifunctional cytokine that regulates cell proliferation, differentiation, migration and survival. It plays a critical role in development, wound healing and immune responses through its regulatory effects on many cell types including epithelial and hematopoietic cells [1]. Three isoforms (TGF $\beta 1, \beta 2$ and $\beta 3$ ), which are encoded

\footnotetext{
* Correspondence: heisterk@hsc.usc.edu

'Division of Hematology/Oncology, Ms\#54, Children's Hospital Los Angeles, 4650 Sunset Boulevard, Los Angeles, CA 90027, USA

Full list of author information is available at the end of the article
}

by different genes and share high homology, have been identified in mammals. TGF- $\beta 1$ is the predominant isoform expressed in immune cells, but all three isoforms have similar properties in vitro. However, in vivo, they have both redundant and distinctive functions because of spatial and temporal expression during development $[2-4]$. TGF $\beta$ signals are transmitted via a cell surface receptor complex consisting of the TGF $\beta$ type I receptor (T $\beta R I)$ and TGF $\beta$ type II receptor (T $\beta R I I)$. To initiate signal transduction, TGF $\beta$ binds to T $\beta$ RII, which in turn recruits T $\beta R I$, leading to the formation of a tetrameric receptor complex. The constitutively active serine/

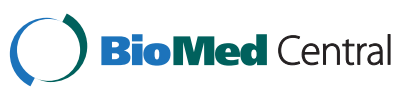


threonine kinase of T $\beta$ RII phosphorylates T $\beta R I$, which activates Smad2 and Smad3 via phosphorylation. Activated Smad2/3 binds Smad4. Subsequently, the Smad2/ $3 / 4$ complex translocates to nucleus to regulate gene expression [5]. Besides the Smad-dependent pathways, TGF $\beta$ also activates the Erk [6], PI3K [7], p38 and JNK [8] pathways, each of which results in a unique pattern of gene expression and thus physiological function.

The importance of TGF $\beta$ signaling in the immune system is highlighted by the finding that mice lacking TGF $\beta 1$ develop a severe lethal wasting syndrome within 3 weeks of birth, associated with a mixed inflammatory cell infiltration and lesions in different organs including the heart and lungs $[9,10]$. Since T $\beta R I I$ is the primary receptor for TGF $\beta$, Leveen et al. [11] generated a conditional ablation model for TGF $\beta$ signaling using $T \beta R I I^{\mathrm{fx} / \mathrm{fx}}$ $\mathrm{x} M x 1$-Cre mice. Upon deletion of the T $\beta R I I$ in the bone marrow of adult mice, a lethal inflammatory disorder that is similar to the phenotype of the TGF $\beta 1$-null mutants was observed. Such lethal disorder was transferable through bone marrow transplantation, indicating that a deficiency of TGF $\beta$ signaling in cells of bone marrow origin is sufficient to cause a lethal inflammatory disease [11]. Further studies on TGF $\beta 1$-null mutants or mice with bone marrow-specific deletion of TRRII showed, that TGF $\beta$ signaling is critical for T-cell immunity [12-14], whereas possible functional defects of macrophages lacking TGF $\beta$ signaling were largely overlooked.

Macrophages are important immune cells that have diverse biological functions, which are, to a large extent, determined by their activation states. Exposure to LPS and IFNY induces macrophages to undergo classical activation and differentiate into M1 macrophages. M1 macrophages are characterized by the production of pro-inflammatory cytokines (TNF $\alpha$ and IL-6) and the induction of iNOS (NOS2), which is essential for generating reactive oxygen species such as $\mathrm{NO}[15,16]$. Because of their pro-inflammatory and cytotoxic activities, M1 macrophages play a critical role in elimination of pathogens and initiation of inflammation. In contrast, when macrophages are exposed to IL-4 (or IL-13), they undergo alternative activation and polarize into M2 macrophages, which are anti-inflammatory. M2 macrophages produce anti-inflammatory cytokines (IL-10) and have increased expression of Arginase-1, which competes with iNOS for a common limiting substrate Larginine [17]. M2 macrophages are primarily involved in phagocytosis of apoptotic cells, resolution of inflammation, tissue repair, and wound healing [18-21].

Although TGF $\beta$ plays a critical role in T-cell immunity, surprisingly, few studies have evaluated the effect of TGF $\beta$ signaling on macrophages. To begin to answer this question, we generated mice lacking T $\beta$ RII and thus
TGF $\beta$ signaling in hematopoietic cells using $T \beta R I I^{f x / f x}$ and Vav1-Cre mice. Vav1-Cre has been shown to direct Cremediated recombination in cells of the hematopoietic lineage [22]. Interestingly, our studies reveal that macrophages lacking T $\beta$ RII have defects in expression of a set of genes that form the hallmark of the M2 polarizing program, suggesting that TGF $\beta$ signaling is needed for the alternative activation of macrophages.

\section{Results}

Mice lacking $T \beta R$ II in hematopoietic cells develop a lethal inflammatory and autoimmune syndrome

Vav1 is a hematopoietic-specific activator for Rac GTPases, and the Vav1 promoter has been widely used to direct expression of genes selectively in the hematopoietic lineage [22]. Thus, in Vav1-Cre $x$ T $R R I^{f x / f x}$ $\left(T \beta R I I^{-1}\right)$ mice, the Vav1-Cre transgene only ablates T $\beta R I I$ in hematopoietic cells. We found that mice lacking T $\beta$ RII function in such cell types were $~ 50 \%$ lighter than wild type (WT) littermates (Figure 1A) and usu-

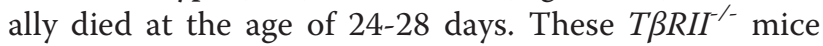
showed classical hallmarks of acute lung inflammation. Total cell numbers in the BALF of TBRII ${ }^{-1}$ mice were significantly higher than those of $W T$ mice (Figure 1B). Whereas BALF cell populations of agematched WT mice consisted, as expected, almost entirely of alveolar macrophages, those of $T \beta R I I^{-/}$mice instead contained many neutrophils, lymphocytes and monocytes (Figure $1 \mathrm{C}$ and $\mathrm{D}$ ).

Mice lacking T $\beta R I I$ in hematopoietic cells exhibited a normal-sized thymus but enlarged lymph nodes and spleen (Figure 1E), which correlated with a greatly increased cellularity of these tissues (Figure $1 \mathrm{~F}$ and G). $T \beta R I I^{\prime-}$ spleens contained increased total neutrophil and T-cell numbers, while total monocyte and B-cell numbers were comparable between genotypes (Figure $1 \mathrm{H}-\mathrm{K}$ ). Strikingly, monocyte numbers in bone marrow, and macrophage infiltration in liver were significantly increased in $T \beta R I I^{-/}$mice (Figure $1 \mathrm{~L}$ and $\mathrm{M}$ ). Since macrophage infiltration in liver is a sign of autoimmune disease, the increased infiltration of macrophages in the livers of $T \beta R I I^{\prime-}$ mice is consistent with the observed inflammatory autoimmune syndrome. We next examined spleen, lymph nodes and thymus for the major T-cell subsets using FACS. Analysis of the thymus showed WT and $T \beta R I^{-}$mice had a similar distribution of $\mathrm{CD} 4^{+}$, $\mathrm{CD}^{+}$and double positive (DP) or double negative (DN) subsets (Additional file 1: Figure S1 A and B). This indicates there were no abnormalities in T-cell development, which is consistent with a previous report that TGF $\beta$ signaling is not required for thymocyte differentiation [12]. We also found that $\mathrm{CD} 25$ expression on $\mathrm{CD} 4^{+} \mathrm{T}$ cells was comparable in thymus, spleen and lymph nodes of $W T$ and $T \beta R I^{-}$mice (Additional file 1: Figure S1C), 


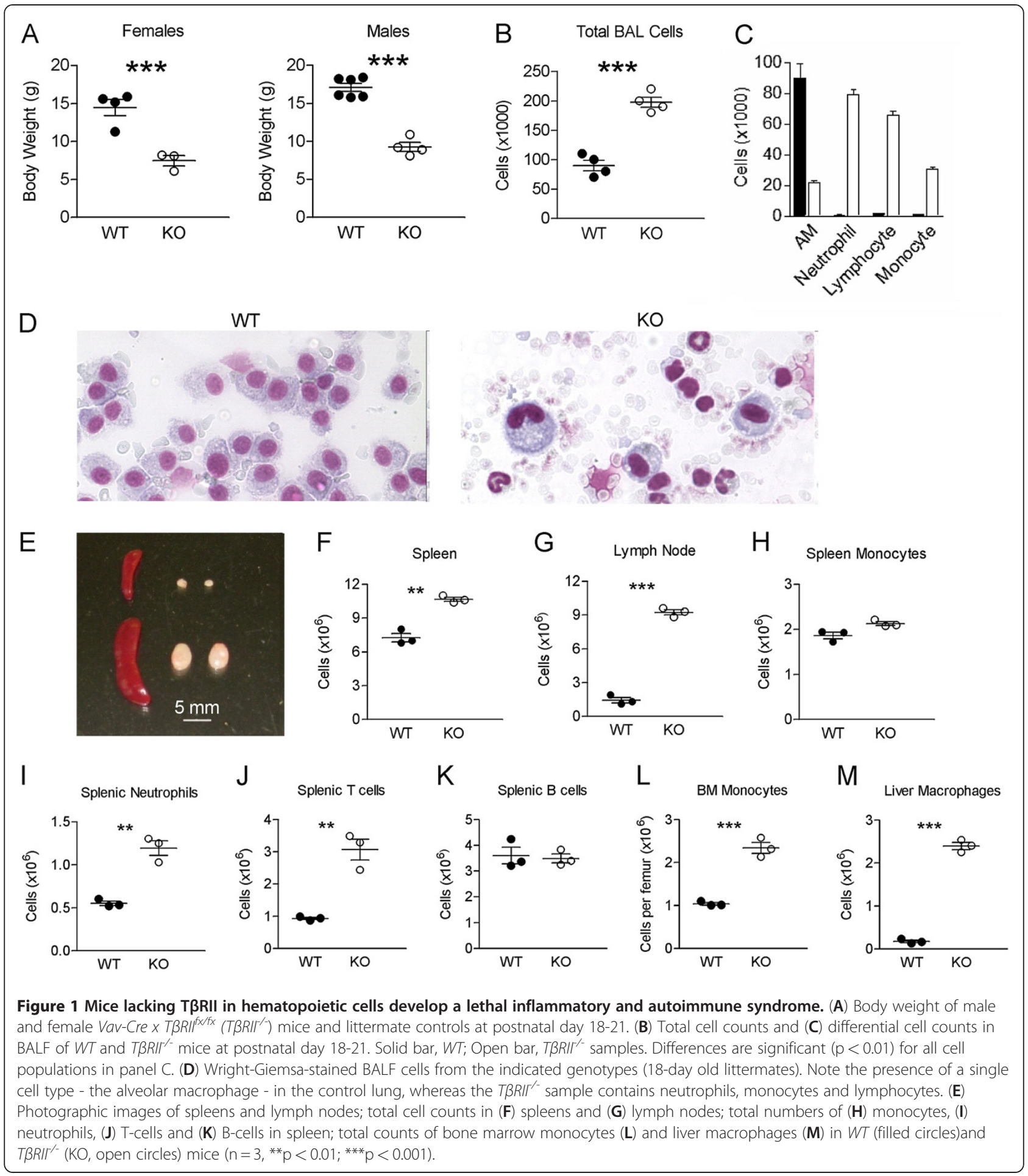

suggesting T $\beta$ RII signaling does not regulate the development of $\mathrm{T}_{\text {reg }}$ cells and consistent with previous studies $[23,24]$.

Analysis of the spleen and lymph nodes showed similar percentages of $\mathrm{CD}_{4}^{+}$and $\mathrm{CD}^{+}$T-cells, although their absolute numbers were increased in $T \beta R I I^{--}$mice (not shown). Interestingly, however, there was a dramatic increase in expression of CD44 on T-cells. Around $20 \%$ of splenic $\mathrm{CD}^{+}{ }^{+} \mathrm{T}$-cells and $40 \%$ of $\mathrm{CD}^{+}$T-cells expressed CD44 in WT mice, while 90-95\% of T-cells lacking T $\beta$ RII had CD44 expression. This was also found in lymph nodes (Additional file 1: Figure S1 E and F). In 
addition, a significantly higher percentage of $\mathrm{CD}^{+} \mathrm{T}$ cells in lymph nodes of $T \beta R I I^{-/-}$mice expressed CD69 (Additional file: 1 Figure S1G). Since CD44 and CD69 are $\mathrm{T}$ cell activation markers, our data indicate that one physiological role of T $\beta$ RII signaling is to suppress $\mathrm{T}$ cell activation.

\section{Expression of M2 markers on BMDMs is impaired in the absence of T $\beta$ RII signaling}

The lack of normal alveolar macrophages in the BALF of $T \beta R I I^{-/}$mice could be associated with intrinsic defects in those macrophages, or could be caused by the environment, since it is well-known that monocytes from the blood can differentiate into different types of macrophages depending upon environmental factors. Treatment with LPS and IFNy will generate classically activated M1 macrophages, whereas treatment with IL-4 and dexamethasone generates M2a and M2c polarized macrophages, respectively. To examine macrophages lacking T $\beta$ RII without the presence of other, possibly confounding, cell types, we isolated bone marrowderived macrophage/monocytes (BMDMs) from the $\mathrm{T} R I I^{-1-}$ mice.

FACS analysis of $W T$ and T $R R I I^{-/}$BMDMs after 11 days in culture with M-CSF, a macrophage growth factor, showed that cells of both genotypes were uniformly Ly6G ${ }^{\text {low }} C D 11 b^{\text {hi }}$ and expressed F4/80, a pan-macrophage surface marker (Additional file 1: Figure S2A), indicating that the purity of the isolated BMDMs is very high ( 99\%). We then treated these BMDMs with stimuli that are typically used to generate different subsets of polarized macrophages. Additional file 1: Figure S2B illustrates that, as reported previously $[15,20,25]$, these stimuli generate morphologically distinct populations. However, BMDMs with or without T $\beta$ RII were morphologically similar. We also investigated the efficiency of Vav1-Cre-mediated ablation of the TGF $\beta$ RII in these cells. Quantitative real-time PCR on DNA from BMDMs showed that, although the deletion was efficient, there was a residual signal of about

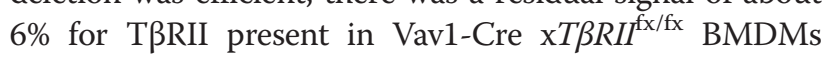
(Additional file 1: Figure S2E).

We next assayed $W T$ and $T \beta R I I^{-/-}$BMDM for their ability to phagocytose apoptotic cells. As shown in Additional file 1: Figure S2C, there were no significant differences in the ability of MO BMDMs with or without TRRII to perform efferocytosis. Next, we polarized them using different agents including LPS/IFNY (M1), IL-4 (M2) and hTGF 31 . BMDMs polarized towards the M1 phenotype had significantly decreased ability to phagocytose dying cells (Additional file 1: Figure S2D), but no significant differences were observed between $W T$ and T $\beta R I I^{\prime-}$ BMDMs. We also tested migration. In contrast to bone-marrow derived neutrophils, which showed significant migration towards $0.1 \mathrm{ng} / \mathrm{ml}$
TGF $\beta 1$, bone marrow-derived macrophages did not migrate towards $5 \mathrm{ng} / \mathrm{ml}$ TGF $\beta 1$ (not shown).

A classical readout for macrophage polarization states is the induction of either iNOS (M1) or Arginase-1 (M2), two enzymes that compete for the common substrate L-arginine. As illustrated in Figure 2A, iNOS was not expressed in M0 or M2 macrophages. Lack of TßRII allowed the normal production of iNOS upon stimulation with LPS/IFN $\gamma$. As reported previously [26], there was a baseline level of Arginase-1 (Arg-1) expression in non-polarized macrophages, which was enhanced by treatment with LPS. Remarkably, $T \beta R I I^{-1-}$ BMDMs had very low baseline levels of Arg-1, showed severely impaired induction of Arg-1 by LPS and had profoundly reduced induction of Arg-1 by IL-4 treatment. Similar defects in Arg-1 expression were obtained when M1polarized (LPS/IFN $\gamma$-treated) $T \beta R I I^{-/}$macrophages were subsequently treated with IL-4 to re-polarize them to an M2 phenotype. Interestingly, macrophages lacking Smad3 had normal induction of Arg-1, indicating that the mechanism is Smad3-independent (Additional file 1: Figure S3).

TGF $\beta 1$ is generally regarded as an anti-inflammatory cytokine and it is frequently listed in the same category as IL-10 and glucocorticoids such as dexamethasone to generate M2c-polarized macrophages. However, we found that WT BMDMs reacted to hTGF $\beta 1$ stimulation with an increased expression of Arg-1 (Figure 2A), similar to the classical M2a stimulus IL-4, whereas dexamethasone (M2c) failed to induce Arg1 (not shown).

To examine if TRRII signaling only regulates Arg-1 expression, or that there are defects in the expression of other M2 markers, we next performed real-time RTPCR for a number of molecules that are typically upregulated in IL-4-polarized macrophages such as $y m 1$, $m r c 2$ and $m g l 1 / 2$ [27-30]. As shown in Figure 2B, lack of TRRII was associated with decreased basal and IL-4induced transcription of arg1 and correlated with decreased transcription of $m c r 2, m g l 2$, and $y m 1$, which are also induced by IL-4. The transcription of $m g l 1$ was not affected. A similar pattern of reduced basal levels of M2 markers was also observed in naïve peritoneal macrophages (Figure 2C). Collectively, our data indicate that TRRII signaling is critical for the optimal expression of genes characteristic for M2 polarization.

\section{Lack of T $\beta R$ II signaling is correlated with decreased galectin-3, $\beta$-catenin and phospho-Akt levels}

The molecular pathways that underlie macrophage polarization are of intense interest due to the importance of this cell type in a wide array of pathologies, ranging from autoimmune disorders to cancer, and the desire to be able to modulate their polarization state. However, there are very few reports of null mutants in 

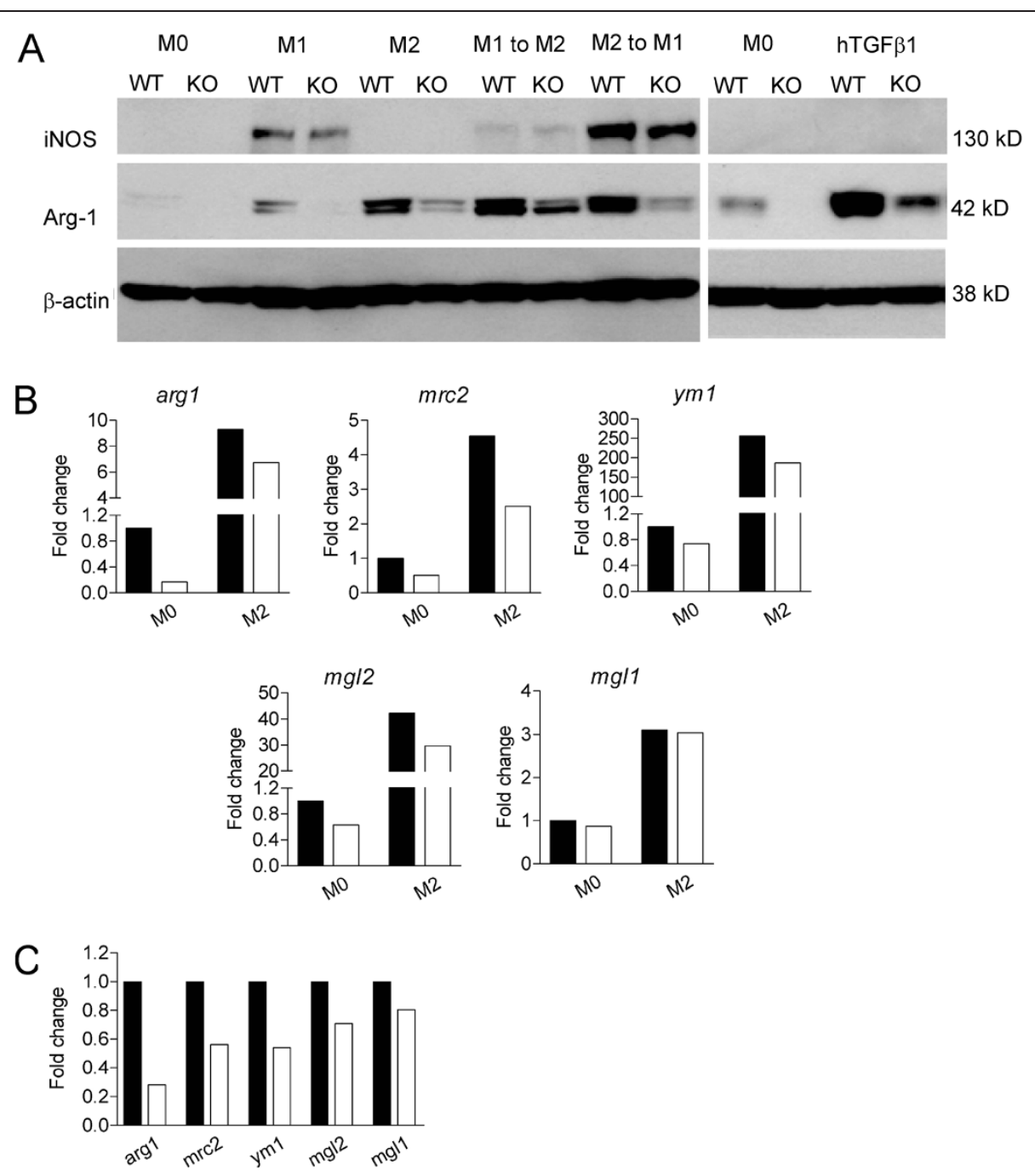

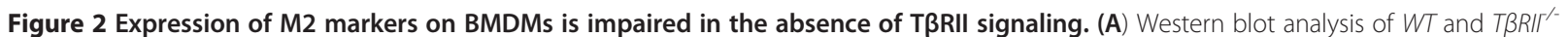
BMDMs cultured for 24 hrs with medium alone (M0), with LPS/IFNy (M1), IL-4 (M2), or hTGF $\beta 1$. $\beta$-actin serves as a loading control. Increased Arg-1 in KO BMDM upon hTGFß1stimulation due to residual WT cells, see Additional file 1: Figure S2E. (B) Real-time RT-PCR for the indicated genes after incubation for 24 hrs with medium alone (M0) or IL-4 (M2). (C) Real-time RT-PCR for the indicated genes in naïve peritoneal macrophages. Fold change is with respect to the expression level of MO WT. Solid bar, WT; Open bar, TBRII- peritoneal macrophages. The results shown are representative of one of two independently derived sets of BMDMs from different mice.

which macrophage polarization defects have been reported. One of these is Galectin-3 (lgals3). Macrophages lacking Galectin-3 show impaired IL-4stimulated M2 polarization and lgals3 null mutants have reduced TGF $\beta$-associated liver fibrosis [31,32].

We therefore performed real-time RT-PCR for lgals3. Interestingly, $T \beta R I I^{--}$BMDMs stimulated with IL-4 had reduced mRNA levels of lgals3 (Figure 3A). To examine this in more detail, we stimulated $W T$ and $T \beta R I I^{-1}$ BMDMs with different polarizing agents and measured cell surface Galectin-3 expression using FACS. Whereas the expression of cell surface CD11b was comparable in these different treatment conditions (not shown), BMDMs lacking TRRII showed clearly decreased
Galectin-3 expression, especially when exposed to LPS/ IFNY (Figure 3B).

The E-cadherin/ $\beta$-catenin complex was recently shown to be a selective marker for alternatively activated macrophages [33]. Interestingly, when $W T$ and $T \beta R I I^{--}$ BMDMs were stimulated by IL-4, $\beta$-catenin levels were $\sim 35 \%$ lower in $T \beta R I I^{-}$than in WT BMDMs (Figure 3C), further indicating that T $\beta$ RII signaling promotes M2 macrophage polarization.

To explore the mechanism by which TGF $\beta$ contributes to IL-4-induced M2 polarization, we examined the downstream targets of IL-4. STAT6 phophorylation is a key signaling event downstream of the IL-4 receptor complex, and Akt also becomes activated in this pathway 


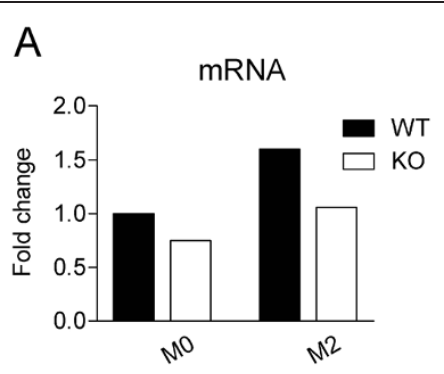

\section{B}
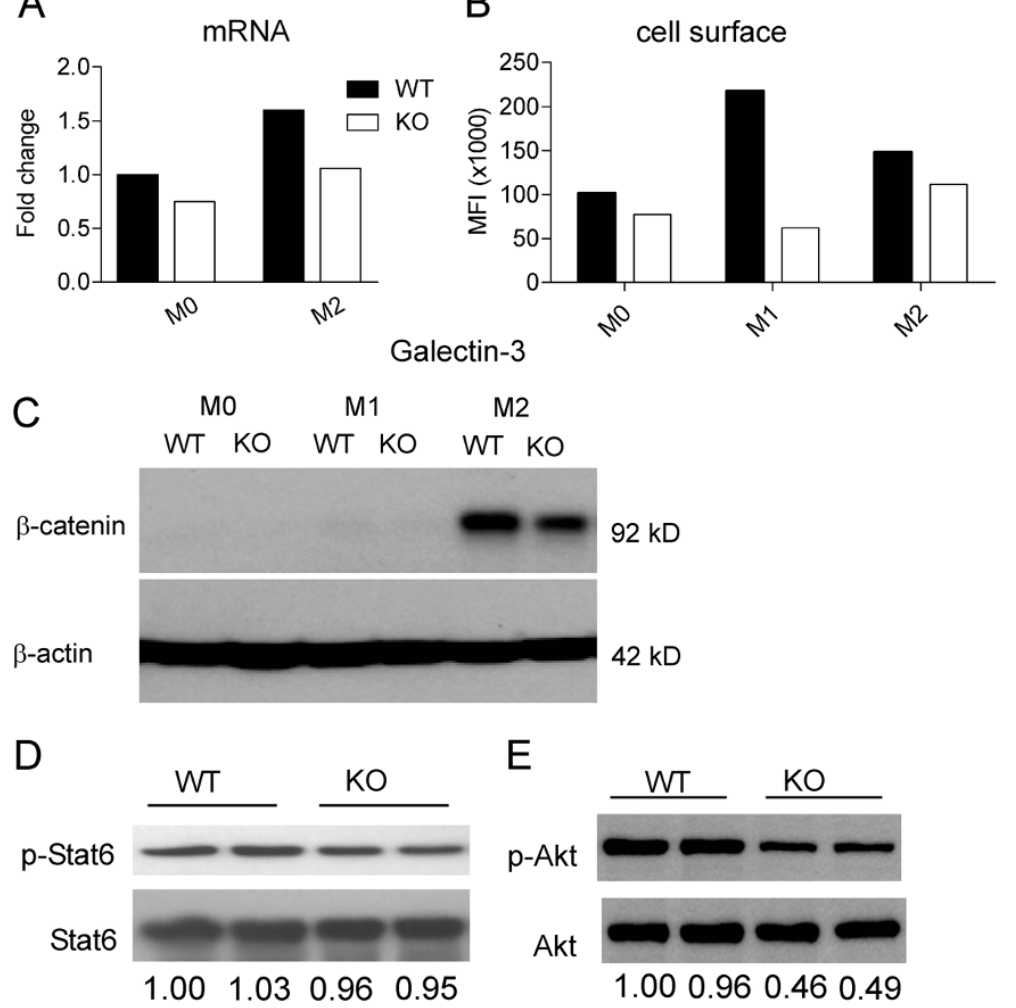

Figure 3 Lack of TRRII signaling is correlated with decreased Galectin-3, $\boldsymbol{\beta}$-catenin and phospho-Akt levels. (A) Real-time RT-PCR for lgals3 in BMDMs. Fold change is with respect to the expression of MO WT. Solid bar, WT; Open bar, TRRI/ ${ }^{-1}$. (B) Cell surface expression of Galectin-3 on WT and TRRII - BMDMs measured using FACS. MFI, mean fluorescent intensity. The result shown is representative of one of two independently derived sets of BMDMs from different mice for both $\mathrm{A}$ and $\mathrm{B}$. (C) Western blot analysis of $\beta$-catenin expression. BMDM were treated with medium alone (M0), LPS/IFNY (M1), or IL-4 (M2). Results are representative of 3 pairs of matched WT and TRRII ${ }^{--}$mice. Western blot analysis of

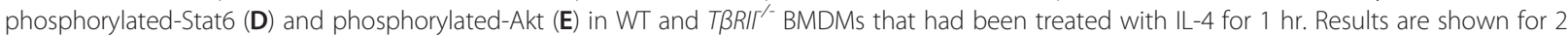
independent mice per genotype. The numbers at the bottom represent the band intensity ratio of phosphorylated protein versus total protein, normalized to lane 1 on each blot.

[34-36]. Thus we investigated if STAT6 and/or Akt are also involved in the IL- 4 stimulated polarization that is co-regulated by TGF $\beta$ signaling. As shown in Figure 3D, p-Stat6 levels were comparable in $W T$ and $T \beta R I I^{-/-}$ BMDMs stimulated with IL-4. However, p-Akt was decreased $\sim 50 \%$ in the absence of TGF $\beta$ signaling (Figure 3E). This indicates that TGF $\beta$ contributes to IL4-induced M2 polarization through co-signaling to Akt, which is one of the TGF $\beta 1$ non-Smad-associated signal transduction pathways reported in other cell types $[37,38]$.

\section{Discussion}

In the current study, we found that the phenotype of mice born without T $\beta$ RII function in hematopoietic cells overlaps with that of mice born without systemic TGF $\beta 1$ production. In both cases, the null mutants develop a severe wasting syndrome at around the same time, at 3 weeks of age $[9,10]$. However, our mice exhibited splenomegaly and lymph node enlargement with a corresponding large increase in cellularity, whereas Shull et al. reported reduced size of spleen and Peyer's patches [10].

We measured dramatically increased expression (15-40\% in WT, 80-95\% in $\mathrm{KO}$ ) of the activation marker CD44, a receptor for the extracellular matrix (ECM) protein hyaluronic acid, on both $\mathrm{CD}^{+}$and $\mathrm{CD}^{+} \mathrm{T}$ cells in the spleen and lymph nodes. Similarly increased CD44 expression was also observed in mice transplanted with bone marrow of mice transgenic for a dominant negative TßRII construct [39]. CD69 is a C-type lectin that is expressed on the surface of all leukocytes during activation, and engagement of CD69 maintains high expression of membrane-bound TGF $\beta 1$ on T-cells [40]. We found that the numbers of $\mathrm{CD}^{+}$and $\mathrm{CD}^{+} \mathrm{T}$-cells in the lymph nodes that expressed CD69 were around twice that of control cells. This result is consistent with the increased numbers of $\mathrm{CD} 9^{+} \mathrm{T}$-cells found in the lymph nodes of mice transplanted with bone marrow from $T \beta R I I^{\mathrm{fx} / \mathrm{fx}} \mathrm{x} M x 1-C r e$ mice and with the signs of T-cell activation in lymph nodes and spleen in those mice [12]. 
Alveolar macrophages are a specialized subclass of differentiated tissue macrophages that are generally regarded as regulatory and anti-inflammatory [41]. At three weeks of age, Vav1-Cre $x T \beta R I I^{\mathrm{f} / \mathrm{fx}}$ mice developed spontaneous pulmonary inflammation in which few normal alveolar macrophages were found. The lack of normal alveolar macrophages could be explained by the pro-inflammatory environment in the lung, which would polarize peripheral blood monocytes that migrate into the lung to an M1 phenotype and/or by re-polarization of alveolar macrophages into proinflammatory M1 macrophages. Also, reduced production of monocytes in the bone marrow could result in lower levels of alveolar macrophages. However, we did not find increased levels of IFN $\gamma$, a classic proinflammatory cytokine, in the peripheral blood of the null mutant mice (Additional file 1: Figure S4) and there was no evidence for impaired generation of monocytes in the bone marrow of mice lacking hematopoietic T $\beta$ RII.

To examine possible macrophage-intrinsic defects, we studied naïve, bone-marrow derived monocyte/macrophages for possible cell-intrinsic defects. This analysis showed an overall decreased ability of macrophages lacking T $\beta R I I$ signaling to produce the normal amounts of arg1 mRNA and protein, either at basal levels or, more markedly, when BMDMs were polarized towards an M2 phenotype with IL-4. In agreement with the regulation of Arg- 1 by TGF $\beta 1$, we found increased expression of Arg-1 in WT macrophages stimulated with this cytokine. Moreover, transcription of other M2 markers including $m g l 2, y m 1$ and $m c r 2$, but not $m g l 1$, was also deceased in $T \beta R I I^{-1-}$ BMDMs, showing that signals through T $\beta R I I$ modulate the M2 transcription program.

$\mathrm{Ym} 1$ is a secretory lectin that promotes Th2 cytokine expression [42], whereas Mrc2 is a C-type receptor for mannose that promotes remodeling of the ECM and the uptake and degradation of collagen [29]. Both Mgl1 (clec10a) and Mgl2 as markers for alternatively activated macrophages are type $\mathrm{C}$ galactose-binding lectins with a different binding specificities to carbohydrate structures [43]. These results show that TGF $\beta$ signaling is responsible for the transcriptional upregulation of several M2polarization genes in macrophages that are important for binding to carbohydrate structures present in the ECM and on other cells and are consistent with the role of TGF $\beta$ as a master regulator of ECM reorganization $[44,45]$.

We also found that macrophages lacking T $\beta$ RII produce less mRNA for lgals3, which encodes a $\beta$-galactosidebinding lectin, and have markedly reduced Galectin-3 cell surface expression on M1 (LPS/IFN $\gamma$-polarized) macrophages. Interestingly, Galectin-3 negatively regulates LPSinduced inflammation [46]. Moreover, BMDMs lacking lgals3 have reduced Arg-1 production and are defective in
M2 polarization [32]. These results suggest that some of the defects in TBRII ${ }^{-1-}$ BMDMs could be caused by the reduced Galectin-3 in those cells. Importantly, Akt phosphorylation was decreased in the IL-4-polarized M2 $T \beta R I I^{--}$BMDMs. This suggests that TGF $\beta$ and IL-4 cosignal to maximally activate the Akt pathway. Although further experiments will be needed to determine the detailed molecular mechanisms through which TGF $\beta$ regulates M2 polarization, our findings suggest that modulation of the TGF $\beta$ signaling pathway may be a method to medically regulate macrophage polarization.

\section{Conclusions}

Taken together, our results establish a critical biological role for TGF $\beta$ signaling in promoting the alternative activation of macrophages. Moreover, our results suggest a distinct contribution of monocytes/macrophages to the systemic inflammation observed in mice with defective T $\beta$ RII function, because lack of T $\beta$ RII signaling in macrophages inhibits the polarization of macrophages to an anti-inflammatory M2 phenotype, this could lead to defective down-regulatory interactions with other immune cells such as T-cells in the lung. These findings further advance our knowledge of the physiological role of TGF $\beta$ signaling and enhance our understanding of the regulation of macrophage activation states.

\section{Methods \\ Animals}

The TBRIF ${ }^{f x / f x}$ mice [47] on a C57BL/6 background were obtained from the NCI Mouse Repository (Strain number: 01XN5) and were bred to Vav1-Cre mice, which were generously provided by Dr. Dimitris Kioussis (National Institute for Medical Research, UK) [22], to generate Vav1Cre $x T \beta R I I^{f x / f x}$ mice and littermate controls. TRRII ${ }^{\prime-}$ mice develop a wasting syndrome 24-28 days after birth. All animal studies were approved by the Institutional Animal Care and Use Committee (IACUC) of Children's Hospital Los Angeles.

\section{Bronchoalveolar lavage}

To prepare BALF, tracheas were exposed and cannulated with an 18-gauge angiocath. Lungs were lavaged five times with $0.8 \mathrm{ml}$ of cold sterile PBS. Analysis of resident and recruited cells was performed on cells pooled from the five washes.

\section{Cytospin and differential staining}

50-80,000 cells were spun onto glass slides at $800 \mathrm{rpm}$ for $5 \mathrm{~min}$ in a Shandon Cytospin II Cytocentrifuge. Slides were stained using a Kwik-Diff stain kit (Thermo Fisher Scientific). Cells were differentially (morphologically) counted using light microscopy. 


\section{Tissue culture and isolation of bone marrow-derived macrophages and peritoneal macrophages}

Tissue culture reagents were from Invitrogen. LPS (cat no. L2630) was from Sigma-Aldrich. IL-4, hTGF 31 , IL10 and IFN $\gamma$ were purchased from PeproTech. The L929 cell line was from the American Type Culture Collection. The supernatant collected from L929 cultures that had grown for 7 days was used to prepare L929 conditioned media, as a source of M-CSF, for macrophage maturation and expansion. Bone marrow-derived macrophages (BMDMs) were prepared by maturing bone marrow cells, which were isolated from femur and tibiae of mice, in DMEM containing 15\% FBS and 20\% L929 conditioned media for 11 days. BMDMs were expanded and treated with IFNy $(10 \mathrm{ng} / \mathrm{ml})$ and LPS $(100 \mathrm{ng} / \mathrm{ml})$ for M1 polarization and IL-4 (10 ng/ml) for M2 polarization. BMDMs were also treated with hTGF $\beta 1$ at $5 \mathrm{ng} / \mathrm{ml}$ or dexamethasone at $40 \mathrm{ng} / \mathrm{ml}$. Peritoneal cells were harvested from the peritoneal cavity of mice by lavage. Cells from 3-4 mice of the same genotype were pooled and stained for FITC-Ly6G, PE-CD11b, PerCPCD45 and APC-F4/80. Peritoneal macrophages (CD45 ${ }^{+} \mathrm{CD} 11 \mathrm{~b}^{+} \mathrm{Ly}_{6 \mathrm{G}}{ }^{-} \mathrm{F} 4 / 80^{+}$) were sorted out using a BD FACSAria Sorter. Sorted cells were lyzed in Trizol reagent (Invitrogen) for total RNA extraction.

\section{Real-time RT-PCR}

Total RNA was prepared using RNeasy kits (Qiagen). cDNA was synthesized using a First Strand cDNA Synthesis kit (Invitrogen). The cDNA was amplified by 40 two-step cycles $\left(15 \mathrm{sec}\right.$ at $95^{\circ} \mathrm{C}$ for denaturation of the $\mathrm{DNA}, 1 \mathrm{~min}$ at $60^{\circ} \mathrm{C}$ for primer annealing and extension). cDNA was analyzed using a SYBR green-based quantitative fluorescence method (Applied Biosystems) in duplicate. The PCR primers were as follows:

GAPDH: forward 5'-AGA GGG AAA TCG TGC GTG AC-3', reverse 5'-CAA TAG TGA TGA CCT GGC CGT-3'; ym1: forward 5'-AGA AGG GAG TTT CAA ACC TGG G-3', reverse 5'-GTC TTG CTC ATG TGT GTA AGT GA-3'; arginase 1: forward 5'-CTC CAA GCC AAA GTC CTT AGA G-3', reverse 5'-AGG AGC TGT CAT TAG GGA CAT C-3'; marc2: forward 5'-TAC AGC TCC ACG CTA TGG ATT-3', reverse 5'CAC TCT CCC AGT GTA GGT ACT-3'; $m g l 1$ : forward 5'-TGA GAA AGG CTT TAA GAA CTG GG-3', reverse 5'-GAC CAC CTG TAG TGA TGT GGG-3'; $m g l 2$ : forward 5'-TTA GCC AAT GTG CTT AGC TGG-3', reverse 5'-GGC CTC CAA TTC TTG AAA CCT'-3'; lgals3: forward 5'-TTG AAG CTG ACC ACT TCA AGG TT-3', reverse 5'- AGG TTC TTC ATC CGA TGG TTG T-3'; TßRII: forward 5'-GGG ATT GCC ATA GCT GTC AT-3'; reverse 5'-TGA TGG CAC AAT TGT CAC TG-3'.

\section{Flow cytometry and quantification of different cell populations in tissues}

Data on fluorochrome-labeled monoclonal antibodystained cells were acquired on an Accuri cytometer (Accuri Cytometers Inc). Data were analyzed using the Accuri software provided by the manufacturer. FITCLy6G, FITC-CD4, PE-CD8, PE-CD25, APC-CD69, APCCD44, PE-Gal 3, PerCP-CD45, and APC-CD11b, were from BioLegend.

For quantification of different cell populations in tissues (spleen, lymph node, thymus, bone marrow and liver), tissues were harvested and processed for total live cell counts using Trypan blue and a hemacytometer. Cells were then stained with appropriate antibodies. The percentages of cell populations were calculated using Accuri software. The total cell number for each leukocyte subset was calculated by multiplying total cell counts with the percentage of that specific cell population within the total cell population.

\section{Efferocytosis assay}

The ability of BMDM to perform phagocytosis of apoptotic cells (efferocytosis) was tested on apoptotic primary thymocytes isolated from 2-4-week old WT mice. After red blood cell lysis, thymocytes were cultured overnight in RPMI 1640 supplemented with 10\% FBS, L-glutamine, sodium pyruvate, penicillin/streptomycin and $50 \mu \mathrm{M} \beta$ mercaptoethanol, with $6 \mu \mathrm{M}$ CFDA. Thymocytes were induced to undergo apoptosis by treatment of $5 \times 10^{6}$ cells/ml with $1 \mu \mathrm{M}$ dexamethasone for $6 \mathrm{hrs}$, which was monitored by annexin V-FITC/propidium iodide staining and FACS. BMDM were starved for $24 \mathrm{hr}$ without CSF-1 in DMEM + 15\% FBS; in some experiments, polarizing cytokines were added. After a wash with cold DMEM, BMDM and thymocytes were preincubated at a ratio of 1:40 on ice. Efferocytosis was initiated by addition of prewarmed DMEM/15\% FBS, followed by incubation at $37^{\circ} \mathrm{C}$ for different times. Controls kept on ice showed no engulfment of apoptotic thymocytes. After co-incubation, cells were washed three times in ice-cold PBS-/- and background fluorescence was quenched on ice for $15 \mathrm{~min}$. with $0.25 \mathrm{mg} / \mathrm{ml}$ Trypan blue in $0.02 \mathrm{M}$ ammonium acetate, $150 \mathrm{mM} \mathrm{NaCl}, \mathrm{pH}$ 4.0. Cells were washed 3 times, fixed and stained with TRITC-phalloidin. Phagocytosis was evaluated by counting 200-300 macrophages per slide from triplicate experiments. Results for the phagocytosis index are expressed as the percentage of macrophages that had engulfed one or more thymocyte.

\section{Western blots}

Cell lysates were resolved by SDS-PAGE and immunoblotted with anti-Arginase-1 (BD Bioscience), antiphospho-Stat6 (Tyr641, Millipore), anti-phospho-Akt 
(Ser473), anti- $\beta$-catenin, and anti-iNOS antibodies (Cell Signaling). Blots were stripped and re-blotted with anti- $\beta$-actin (Sigma), anti-GAPDH (Millipore), antiStat6 or anti-Akt (Cell Signaling) antibodies. Band intensities were analyzed using Un-Scan-It software (Silk Scientific, Orem, UT) on the scanned images of the blots.

\section{ELISA}

Blood was collected from $W T$ and $T \beta R I I-/$ - mice at postnatal day 18-21. After clotting of blood, serum was harvested by centrifugation at $800 \mathrm{~g}$ for $10 \mathrm{~min}$. Serum IFN $\gamma$ levels were measured using a mouse IFN $\gamma$ ELISA kit (Biolegend) according to the manufacturer's protocol.

\section{Statistical analysis}

Data are expressed as mean \pm SEM and analyzed by the unpaired Student's $t$ test using Prism (GraphPad) software, unless indicated otherwise in the figure legend. $p<0.05$ was considered to be statistically significant.

\section{Additional file}

Additional file 1: Figure S1. Analysis of T-cells in thymus, spleen and lymph nodes of WT and TRRII-/- mice. (A) FACS of WT and TBRII-/- thymus for CD4- and CD8-positive cells. (B) Cell counts of double negative (DN), double positive (DP), CD4 single positive and CD8 single positive cells in thymus. (C) Percentage of CD4 + CD25+ T-cells in thymus, lymph node and spleen of $W T$ and TBRII-/- mice. Solid bar, WT; Open bar, TBRII-/- mice. (D) Left, single-cell suspensions of lymph nodes were gated for lymphocytes (P1) and right, CD4+ and CD8+ T cells. (E) Representative histogram of CD44 expression on CD4+ T cells of TBRIl-/- (red line) and control (black line) mice. (F) Percentage of CD44+ cells in spleen and lymph nodes using the strategy in (D). (G) Percentage of CD69+ cells in lymph nodes. ${ }^{* *}, p<0.05 ;{ }^{* * *} p<0.005$. Figure S2 BMDMs with or without TRRll function. (A) Gating strategy for FACS on BMDMs of the indicated genotypes using CD11b and Ly6G. Right panel, the expression of F4/80, a pan-macrophage surface marker. (B) BMDMs were treated with the stimuli as indicated to the right for $24 \mathrm{hrs}$. Representative phase contrast images are shown. (C) Percentage BMDMs that had engulfed at least one apoptotic thymocyte (efferocytosis) in standard medium. (D) Efferocytosis of BMDMs with or without TBRll function treated for $24 \mathrm{hrs}$ with medium alone (M0); $100 \mathrm{ng} / \mathrm{ml}$ LPS and $10 \mathrm{ng} / \mathrm{ml}$ IFNy (M1), $10 \mathrm{ng} / \mathrm{ml} \mathrm{IL-4} \mathrm{(M2a),}$ or $5 \mathrm{ng} / \mathrm{ml} \mathrm{hTGF \beta 1.} \mathrm{M0} \mathrm{compared} \mathrm{to} \mathrm{M1,}{ }^{* *} \mathrm{p}=0.003$. (E) Genomic DNA was extracted from $W T$ and TRRII-/- BMDMs $(n=4)$. Real-time PCR was

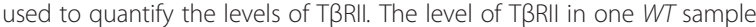
was set to 1 and the levels of TRRII in other samples were normalized to that of the chosen WT sample. Figure S3 Expression of iNOS and Arg1 in WT and smad3-/- BMDMs. Western blot analysis of Arg1 and iNOS in BMDMs of WT and smad3-/- mice. Figure S4 IFNY levels in the blood of WT and TBRII-/- mice. ELISA was used to measure IFNY levels in the serum of $W T$ and TRRII-/- mice on postnatal day 18-21 $(n=4)$.

\section{Abbreviations}

BAL: Bronchoalveolar lavage; BALF: Bronchoalveolar lavage fluid BMDMs: Bone marrow-derived macrophages; ECM: Extracellular matrix; TGF $\beta$ : Transforming growth factor beta; T $\beta R I I$ : TGF $\beta$ type II receptor.

\section{Competing interests}

The authors declare that they have no competing interests.

\section{Acknowledgements}

We thank Dr. Dimitris Kioussis (National Institute for Medical Research, UK) for providing the Vav1-Cre transgenic mice, and Donna Foster for excellent care of the mice. This work was supported by the National Institutes of Health (HL071945 and HL060231 to JG).

\section{Author details}

'Division of Hematology/Oncology, Ms\#54, Children's Hospital Los Angeles, 4650 Sunset Boulevard, Los Angeles, CA 90027, USA. ${ }^{2}$ Developmental Biology and Regenerative Medicine Program, Saban Research Institute, Children's Hospital Los Angeles, Los Angeles, CA, USA.

\section{Author's contributions}

DG designed and performed experiments, collected and analyzed data, and drafted the manuscript. SY designed and performed the efferocytosis and motility assays. WS and HC provided Vav1-Cre and TGFRRIIt/fx mice and revised the manuscript. $\mathrm{NH}$ and JG designed and coordinated experiments, evaluated and interpreted data, and prepared the manuscript. All authors read and approved the manuscript.

Received: 31 December 2011 Accepted: 15 June 2012

Published: 15 June 2012

\section{References}

1. Blobe GC, Schiemann WP, Lodish HF: Role of transforming growth factor beta in human disease. N Engl J Med 2000, 342:1350-1358.

2. Iseki S, Osumi-Yamashita N, Miyazono K, Franzen P, Ichijo H, Ohtani H, Hayashi $Y$, Eto K: Localization of transforming growth factor-beta type I and type II receptors in mouse development. Exp Cell Res 1995, 219:339-347.

3. Millan FA, Denhez F, Kondaiah P, Akhurst RJ: Embryonic gene expression patterns of TGF beta 1, beta 2 and beta 3 suggest different developmental functions in vivo. Development 1991, 111:131-143.

4. Roberts AB, Sporn MB: Differential expression of the TGF-beta isoforms in embryogenesis suggests specific roles in developing and adult tissues. Mol Reprod Dev 1992, 32:91-98.

5. Li MO, Wan YY, Sanjabi S, Robertson AK, Flavell RA: Transforming growth factor-beta regulation of immune responses. Annu Rev Immunol 2006, 24:99-146.

6. Reimann T, Hempel U, Krautwald S, Axmann A, Scheibe R, Seidel D, Wenzel KW: Transforming growth factor-beta1 induces activation of Ras, Raf-1, MEK and MAPK in rat hepatic stellate cells. FEBS Lett 1997, 403:57-60.

7. Bakin AV, Tomlinson AK, Bhowmick NA, Moses HL, Arteaga CL: Phosphatidylinositol 3-kinase function is required for transforming growth factor beta-mediated epithelial to mesenchymal transition and cell migration. J Biol Chem 2000, 275:36803-36810.

8. Yamashita M, Fatyol K, Jin C, Wang X, Liu Z, Zhang YE: TRAF6 mediates Smad-independent activation of JNK and p38 by TGF-beta. Mol Cell 2008, 31:918-924.

9. Kulkarni $A B$, Huh $C G$, Becker D, Geiser A, Lyght M, Flanders KC, Roberts AB, Sporn MB, Ward JM, Karlsson S: Transforming growth factor beta 1 null mutation in mice causes excessive inflammatory response and early death. Proc Natl Acad Sci U S A 1993, 90:770-774.

10. Shull MM, Ormsby I, Kier AB, Pawlowski S, Diebold RJ, Yin M, Allen R, Sidman C, Proetzel G, Calvin D, et al: Targeted disruption of the mouse transforming growth factor-beta 1 gene results in multifocal inflammatory disease. Nature 1992, 359:693-699.

11. Leveen P, Larsson J, Ehinger M, Cilio CM, Sundler M, Sjostrand LJ, Holmdahl $\mathrm{R}$, Karlsson S: Induced disruption of the transforming growth factor beta type II receptor gene in mice causes a lethal inflammatory disorder that is transplantable. Blood 2002, 100:560-568.

12. Leveen P, Carlsen M, Makowska A, Oddsson S, Larsson J, Goumans MJ, Cilio CM, Karlsson S: TGF-beta type II receptor-deficient thymocytes develop normally but demonstrate increased CD8+ proliferation in vivo. Blood 2005, 106:4234-4240.

13. Li MO, Flavell RA: TGF-beta: a master of all T cell trades. Cell 2008, 134:392-404.

14. Li MO, Sanjabi S, Flavell RA: Transforming growth factor-beta controls development, homeostasis, and tolerance of $\mathrm{T}$ cells by regulatory $\mathrm{T}$ cell-dependent and -independent mechanisms. Immunity 2006, 25:455-471. 
15. Gordon S, Taylor PR: Monocyte and macrophage heterogeneity. Nat Rev Immunol 2005, 5:953-964.

16. Mantovani A, Sica A, Sozzani S, Allavena P, Vecchi A, Locati M: The chemokine system in diverse forms of macrophage activation and polarization. Trends Immunol 2004, 25:677-686.

17. Bronte $\mathrm{V}$, Zanovello P: Regulation of immune responses by L-arginine metabolism. Nat Rev Immunol 2005, 5:641-654.

18. Martinez FO, Helming L, Gordon S: Alternative activation of macrophages: an immunologic functional perspective. Annu Rev Immunol 2009, 27:451-483.

19. Mosser DM, Edwards JP: Exploring the full spectrum of macrophage activation. Nat Rev Immunol 2008, 8:958-969.

20. Mosser DM: The many faces of macrophage activation. J Leukoc Biol 2003, 73:209-212.

21. Gordon S: Alternative activation of macrophages. Nat Rev Immunol 2003, 3:23-35.

22. de Boer J, Williams A, Skavdis G, Harker N, Coles M, Tolaini M, Norton T, Williams K, Roderick K, Potocnik AJ, et al: Transgenic mice with hematopoietic and lymphoid specific expression of Cre. Eur J Immunol 2003, 33:314-325.

23. Mamura M, Lee W, Sullivan TJ, Felici A, Sowers AL, Allison JP, Letterio JJ: CD28 disruption exacerbates inflammation in Tgf-beta1-/- mice: in vivo suppression by $\mathrm{CD} 4+\mathrm{CD} 25+$ regulatory $T$ cells independent of autocrine TGF-beta1. Blood 2004, 103:4594-4601.

24. Fahlen L, Read S, Gorelik L, Hurst SD, Coffman RL, Flavell RA, Powrie F: T cells that cannot respond to TGF-beta escape control by CD4(+)CD25(+) regulatory T cells. J Exp Med 2005, 201:737-746.

25. Stout RD, Suttles J: Functional plasticity of macrophages: reversible adaptation to changing microenvironments. J Leukoc Biol 2004, 76:509-513.

26. Klasen S, Hammermann R, Fuhrmann M, Lindemann D, Beck KF, Pfeilschifter J, Racke K: Glucocorticoids inhibit lipopolysaccharide-induced up-regulation of arginase in rat alveolar macrophages. $\mathrm{Br} J$ Pharmacol 2001, 132:1349-1357.

27. Denda-Nagai K, Aida S, Saba K, Suzuki K, Moriyama S, Oo-Puthinan S, Tsuiji M, Morikawa A, Kumamoto Y, Sugiura D, et al: Distribution and function of macrophage galactose-type C-type lectin 2 (MGL2/CD301b): efficient uptake and presentation of glycosylated antigens by dendritic cells. J Biol Chem 2010, 285:19193-19204.

28. Raes G, De Baetselier P, Noel W, Beschin A, Brombacher F, Hassanzadeh Gh G: Differential expression of FIZZ1 and Ym1 in alternatively versus classically activated macrophages. J Leukoc Biol 2002, 71:597-602.

29. Stein M, Keshav S, Harris N, Gordon S: Interleukin 4 potently enhances murine macrophage mannose receptor activity: a marker of alternative immunologic macrophage activation. J Exp Med 1992, 176:287-292.

30. Zhu Z, Zheng T, Homer RJ, Kim YK, Chen NY, Cohn L, Hamid Q, Elias JA: Acidic mammalian chitinase in asthmatic Th2 inflammation and IL-13 pathway activation. Science 2004, 304:1678-1682.

31. Henderson NC, Mackinnon AC, Farnworth SL, Poirier F, Russo FP, Iredale JP, Haslett C, Simpson KJ, Sethi T: Galectin-3 regulates myofibroblast activation and hepatic fibrosis. Proc Natl Acad Sci U S A 2006, 103:5060-5065.

32. MacKinnon AC, Farnworth SL, Hodkinson PS, Henderson NC, Atkinson KM, Leffler H, Nilsson UJ, Haslett C, Forbes SJ, Sethi T: Regulation of alternative macrophage activation by galectin-3. J Immunol 2008, 180:2650-2658.

33. Van den Bossche J, Bogaert P, van Hengel J, Guerin CJ, Berx G, Movahedi K, Van den Bergh R, Pereira-Fernandes A, Geuns JM, Pircher $\mathrm{H}$, et al: Alternatively activated macrophages engage in homotypic and heterotypic interactions through IL-4 and polyamine-induced Ecadherin/catenin complexes. Blood 2009, 114:4664-4674.

34. Rauh MJ, Ho V, Pereira C, Sham A, Sly LM, Lam V, Huxham L, Minchinton Al, Mui A, Krystal G: SHIP represses the generation of alternatively activated macrophages. Immunity 2005, 23:361-374.

35. Jiang $H$, Harris MB, Rothman P: IL-4/IL-13 signaling beyond JAK/STAT. J Allergy Clin Immunol 2000, 105:1063-1070.

36. Giallourakis C, Kashiwada M, Pan PY, Danial N, Jiang H, Cambier J, Coggeshall KM, Rothman P: Positive regulation of interleukin-4-mediated proliferation by the $\mathrm{SH} 2$-containing inositol-5'-phosphatase. J Biol Chem 2000, 275:29275-29282.

37. Lamouille S, Derynck R: Emergence of the phosphoinositide 3-kinase-Aktmammalian target of rapamycin axis in transforming growth factor-beta- induced epithelial-mesenchymal transition. Cells Tissues Organs 2011, 193:8-22.

38. Mu Y, Gudey SK, Landstrom M: Non-Smad signaling pathways. Cell Tissue Res 2012, 347:11-20.

39. Shah AH, Tabayoyong WB, Kimm SY, Kim SJ, Van Parijs L, Lee C: Reconstitution of lethally irradiated adult mice with dominant negative TGF-beta type II receptor-transduced bone marrow leads to myeloid expansion and inflammatory disease. J Immunol 2002, 169:3485-3491.

40. Han Y, Guo Q, Zhang M, Chen Z, Cao X: CD69+ CD4+ CD25- T cells, a new subset of regulatory $T$ cells, suppress $T$ cell proliferation through membrane-bound TGF-beta 1. J Immunol 2009, 182:111-120.

41. Guth AM, Janssen WJ, Bosio CM, Crouch EC, Henson PM, Dow SW: Lung environment determines unique phenotype of alveolar macrophages. Am J Physiol Lung Cell Mol Physiol 2009, 296:L936-L946.

42. Cai Y, Kumar RK, Zhou J, Foster PS, Webb DC: Ym1/2 promotes Th2 cytokine expression by inhibiting 12/15(S)-lipoxygenase: identification of a novel pathway for regulating allergic inflammation. J Immunol 2009, 182:5393-5399.

43. Raes G, Brys L, Dahal BK, Brandt J, Grooten J, Brombacher F, Vanham G, Noel W, Bogaert P, Boonefaes T, et al: Macrophage galactose-type C-type lectins as novel markers for alternatively activated macrophages elicited by parasitic infections and allergic airway inflammation. J Leukoc Biol 2005, 77:321-327.

44. Klass BR, Grobbelaar AO, Rolfe KJ: Transforming growth factor beta1 signalling, wound healing and repair: a multifunctional cytokine with clinical implications for wound repair, a delicate balance. Postgrad Med 2009, 85:9-14.

45. Xu BJ, Yan W, Jovanovic B, An AQ, Cheng N, Aakre ME, Yi Y, Eng J, Link AJ, Moses HL: Quantitative analysis of the secretome of TGF-beta signaling-deficient mammary fibroblasts. Proteomics 2010, 10:2458-2470.

46. Li Y, Komai-Koma M, Gilchrist DS, Hsu DK, Liu FT, Springall T, Xu D: Galectin3 is a negative regulator of lipopolysaccharide-mediated inflammation. J Immunol 2008, 181:2781-2789.

47. Chytil A, Magnuson MA, Wright CV, Moses HL: Conditional inactivation of the TGF-beta type II receptor using Cre: Lox. Genesis 2002, 32:73-75.

doi:10.1186/1471-2172-13-31

Cite this article as: Gong et al:: TGF $\beta$ signaling plays a critical role in promoting alternative macrophage activation. BMC Immunology 2012 13:31.

\section{Submit your next manuscript to BioMed Central and take full advantage of:}

- Convenient online submission

- Thorough peer review

- No space constraints or color figure charges

- Immediate publication on acceptance

- Inclusion in PubMed, CAS, Scopus and Google Scholar

- Research which is freely available for redistribution 